\title{
Penggunaan aplikasi OriginPro untuk analisis spektrum gelombang Petir
}

\author{
${ }^{1 *}$ Fadli Eka Yandra, ${ }^{2}$ Riki Saputra \\ ${ }^{1}$ Teknik Listrik, Fakultas Teknik, Universitas Batanghari \\ ${ }^{2}$ Teknik Sipil, Fakultas Teknik, Universitas Batanghari \\ "Correspondence email: fadli.eka.yandra@unbari.ac.id
}

\begin{abstract}
Abstrak. Penganalisis spektrum mengukur besarnya sinyal input versus frekuensi dalam rentang frekuensi penuh instrumen. Kegunaan utama adalah untuk mengukur kekuatan spektrum sinyal yang diketahui dan tidak dikenal. Sinyal masukan yang paling umum diukur penganalisis spektrum adalah listrik; namun, komposisi spektral dari sinyal lain, seperti gelombang tekanan akustik dan gelombang cahaya optik, dapat dipertimbangkan melalui penggunaan transduser yang sesuai. Penganalisis spektrum untuk jenis sinyal lain juga ada, seperti penganalisis spektrum optik yang menggunakan teknik optik langsung seperti monokromator untuk melakukan pengukuran. Dengan menganalisis spektrum sinyal listrik, frekuensi dominan, daya, distorsi, harmonisa, bandwidth, dan komponen spektral sinyal lainnya dapat diamati yang tidak mudah dideteksi dalam bentuk gelombang domain waktu. Parameter ini berguna dalam karakterisasi perangkat elektronik, seperti pemancar nirkabel. Tampilan spektrum analyzer memiliki frekuensi pada sumbu horizontal dan amplitudo ditampilkan pada sumbu vertikal. Bagi pengamat biasa, penganalisis spektrum terlihat seperti osiloskop dan, pada kenyataannya, beberapa instrumen laboratorium dapat berfungsi sebagai osiloskop atau penganalisis spektrum. Sinyal gelombang petir yang dideteksi dengan menggunakan osiloskop digital, diolah dengan aplikasi OriginPro untuk mendapatkan pola gelombang petir yang terjadi, analisis spektrum sendiri menggunakan perhitungan $F F T$ (fast fourier transform).
\end{abstract}

Kata Kunci: Analisis spektrum; aplikasi OriginPro, FFT

\section{PENDAHULUAN}

Transformasi Fourier adalah metode yang digunakan dengan mendekomposisi sebuah gelombang seismik menjadi beberapa gelombang harmonik sinusoidal. Gelombang harmonik sinusoidal tersebut dianggap sebagai Deret Fourier. Transformasi Fourier ditemukan oleh ilmuwan bernama Joseph Fourier.

Fast Fourier Transform (FFT) adalah algoritma efisien yang digunakan untuk menghitung transformasi Fourier diskrit (DFT). Transformasi Fourier ini mengeluarkan amplitudo getaran sebagai fungsi frekuensi sehingga penganalisis dapat memahami penyebab terjadinya getaran. Resolusi frekuensi dalam FFT berbanding lurus dengan panjang sinyal dan laju sampel. Untuk meningkatkan resolusi, waktu perekaman harus diperpanjang; tapi hati-hati dengan lingkungan getaran yang berubah.

Transformasi Fourier yang digunakan untuk analisis spektrum memiliki tujuan agar sinyal dari domain waktu bisa menjadi sinyal dalam domain frekuensi. Hal ini dilakukan agar perhitungan menjadi lebih mudah, apabila masih dalam domain waktu maka perhitungannya akan lebih sulit. Berikut adalah rumus dari FFT (Atha dkk, 2017)

$X(\omega)=\int_{-\infty}^{\infty \infty} x(t) e^{-j \omega t} d t$

$\mathrm{X}(\omega)$ adalah fungsi dalam domain frekuensi, adalah frekuensi radial $0-2 \pi \mathrm{f}$, atau dapat dituliskan bahwa $\omega=$ $2 \pi \mathrm{f}$.

FFT dapat diaplikasikan dalam beragam bidang dari pengolahan sinyal digital, seperti pada pengolahan Horizontal Vertical Spectral Ratio (HVSR). Dengan dapat merubah hasil data lapangan berupa domain waktu menjadi frekuensi, membuat spektrum horizontal dan vertikal dapat dibandingan sehingga dapat menghasilkan output berupa spektrum yang diinterpretasikan sebagai amplifikasi dan frekuensi natural. Berikut ilustrasi penggambaran perubahan domain waktu ke domain frekuensi pada HVSR.

\section{Spektogram}

Spektogram mengambil serangkaian FFT dan tumpang tindih untuk menggambarkan bagaimana spektrum (domain frekuensi) berubah seiring waktu. Jika analisis getaran dilakukan pada lingkungan yang berubah, spektogram dapat menjadi alat yang ampuh untuk menggambarkan dengan tepat bagaimana spektrum getaran itu berubah. 
PSD

Densitas spektral daya (PSD) mengambil amplitudo FFT, mengalikannya dengan konjugat kompleksnya dan menormalkannya ke lebar bin frekuensi. Hal ini memungkinkan perbandingan yang akurat dari sinyal getaran acak yang memiliki panjang sinyal berbeda. Untuk alasan ini, PSD biasanya digunakan untuk mendeskripsikan lingkungan getaran acak seperti yang ditentukan dalam standar uji militer dan komersial.

\section{METODE}

Menganalisis gelombang petir yang didapat dari hasil pembacaan osiloskop ke analisis FFT dengan menggunakan aplikasi OriginPro. Data yang didapat dari pembacaan osiloskop, seperti gambar berikut, akan dianalisis dengan menggunakan aplikasi OriginPro.

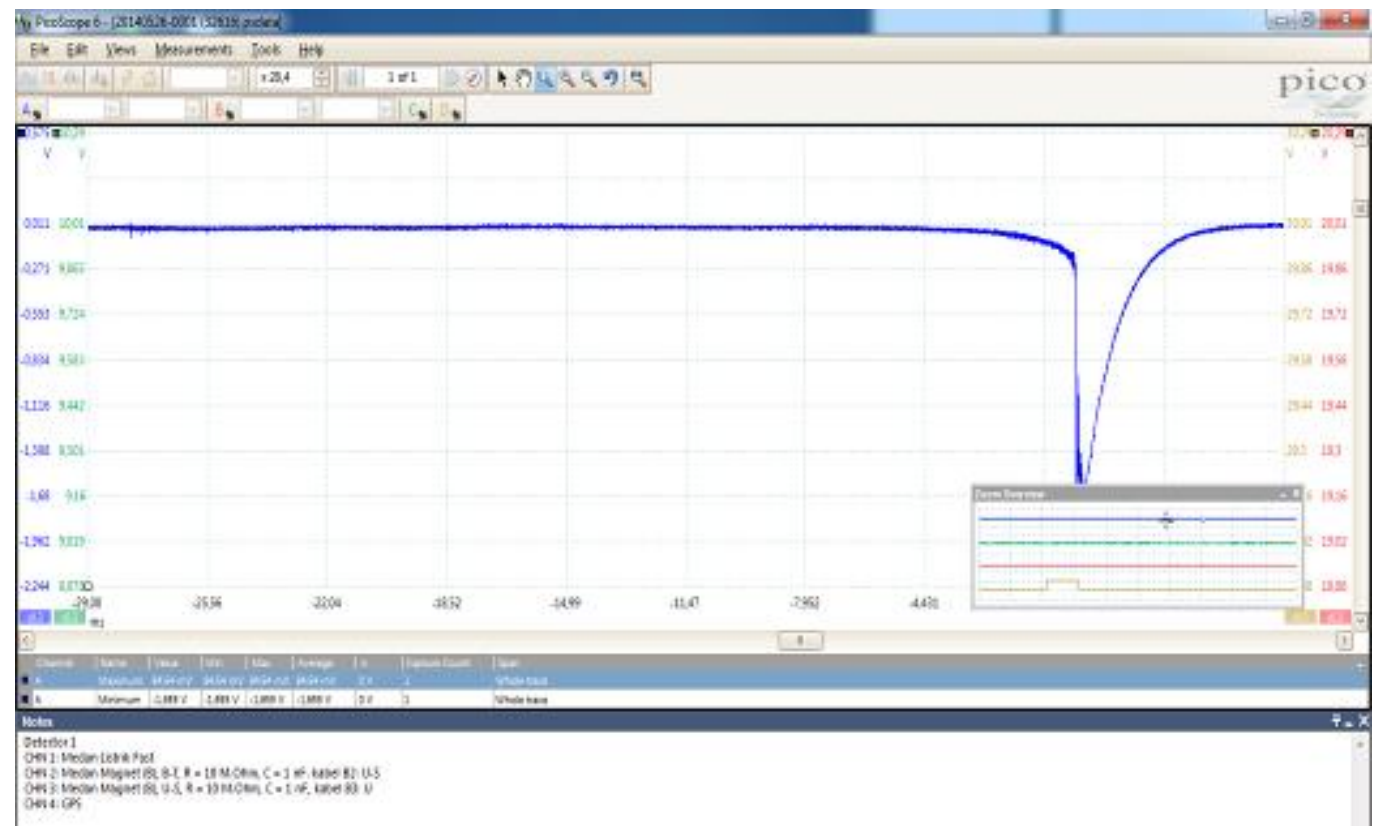

Gambar 1. Sampling rate $1 \mathrm{MS} / \mathrm{s}$ dengan waktu $1 \mathrm{~s}$

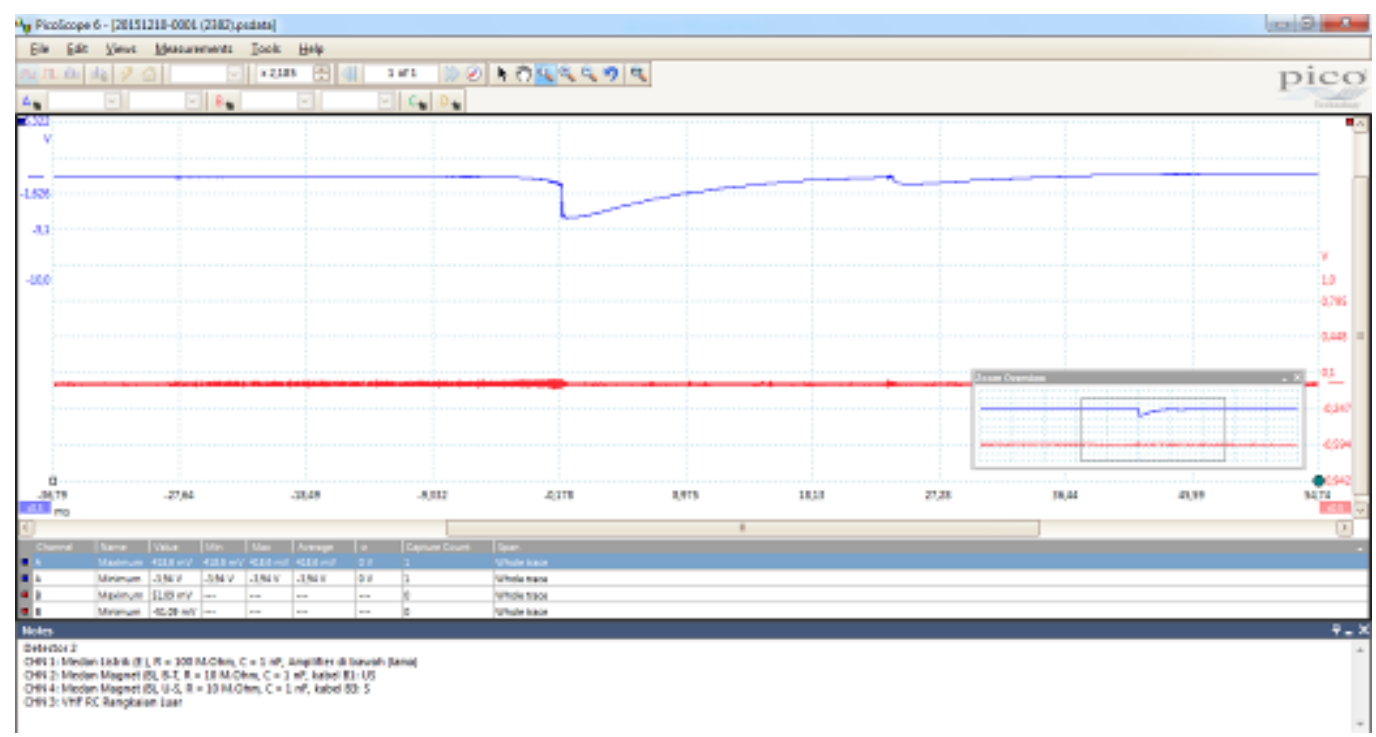

Gambar 2. Sampling rate $25 \mathrm{MS} / \mathrm{s}$ dengan waktu 200ms

Sinyal non-stasioner adalah sinyal yang karakteristik statistiknya bervariasi menurut waktu. Transformasi Fourier klasik tidak terlalu cocok untuk menganalisis jenis sinyal ini karena tidak dapat memberikan informasi apa pun tentang bagaimana frekuensi berubah seiring waktu. Jadi, analisis frekuensi waktu, seperti STFT, harus digunakan. Short-time Fourier Transform (STFT), adalah metode analisis yang digunakan untuk menganalisis sinyal non-stasioner. Ini mengekstrak beberapa frame sinyal dengan Window yang bergerak seiring waktu. Jika Window waktu cukup sempit, setiap bingkai yang diekstraksi dapat dilihat sebagai stasioner sehingga transformasi Fourier dapat digunakan. Dengan Window bergerak sepanjang sumbu waktu, hubungan antara varian frekuensi dan waktu dapat diidentifikasi. 
Urutan STFT yang dilakukan, $\{i x(n)\}$, dapat didefenisikan sebagai berikut :

$\operatorname{STFT}\{x[n]\} \equiv X(m, \omega)=\sum_{n=-\infty}^{\infty} x[n] \omega[n-m] e^{-j w n}$

Dimana $\square$ (n) merepresentasikan pergeseran Windows yang menekan komponen frekuensi lokal didalamnya. Hasil STFT berupa matriks yang memiliki baris $\mathrm{N}$ dan kolom M, dimana:

$N=\left\{\begin{array}{l}\text { FFT Length/2+1, if input signal is real } \\ \text { FFT Length }\end{array}\right.$

dan

$M=$ floor $\left(\frac{\text { Data Size }- \text { Window Size }}{\text { Window Size }- \text { Overlap Size }}\right)+1$

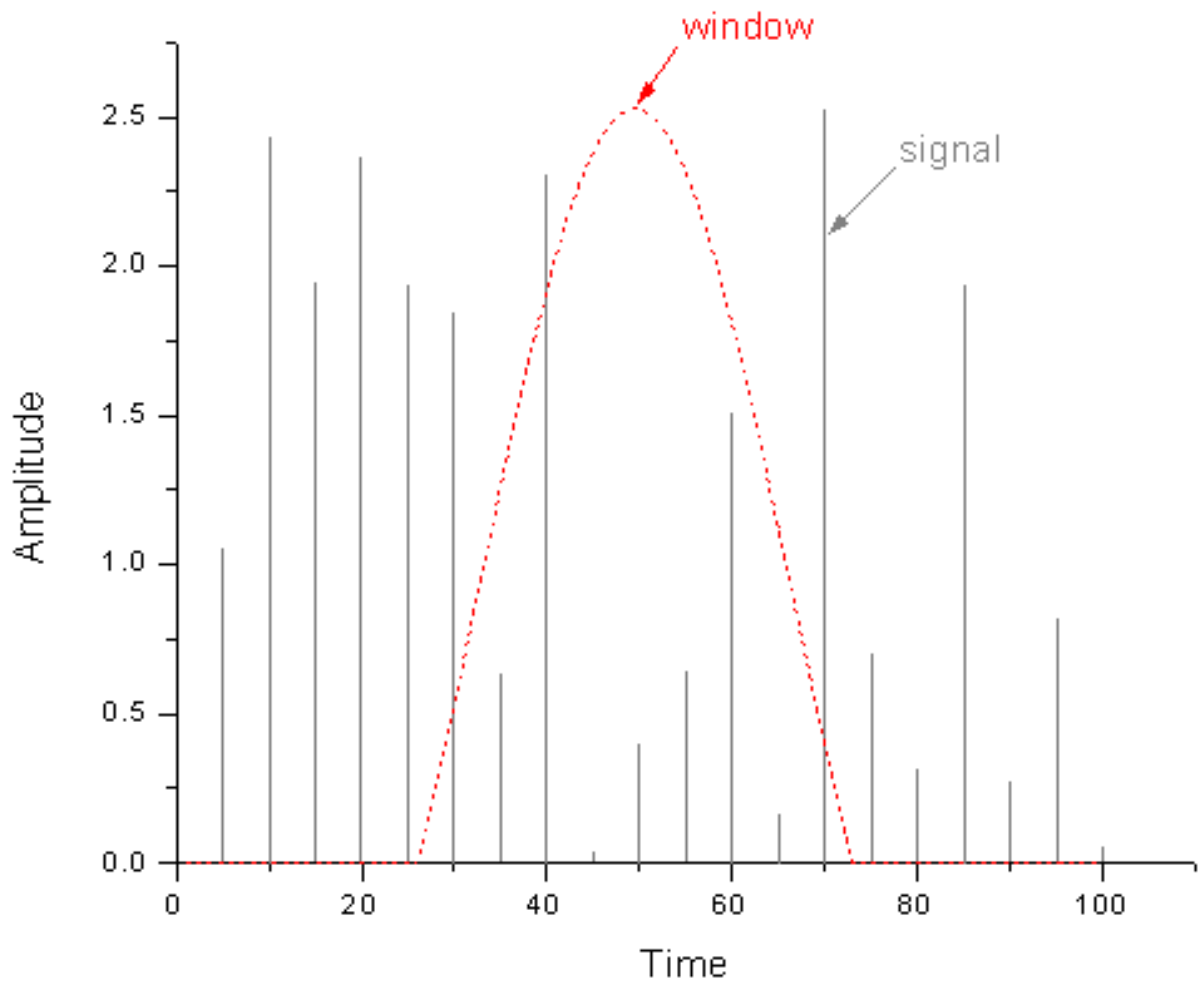

Gambar 3. Hasil analisis STFT

Window yang dipilih dapat memengaruhi analisis. Pengguna harus memperhatikan ukuran dan bentuk Window.

Ukuran Window terkait dengan resolusi waktu dan resolusi frekuensi STFT. Semakin pendek Windownya, semakin tinggi resolusi waktunya. Namun, hal ini biasanya disertai dengan resolusi frekuensi yang buruk. Untuk Window yang panjang, resolusi frekuensinya tinggi, tetapi resolusi waktunya rendah. Fenomena ini mencerminkan prinsip ketidakpastian Heisenberg.

Bentuk Window yang berbeda menghasilkan hasil yang berbeda, dan Origin menyediakan hingga sembilan Window berbeda untuk memenuhi kebutuhan khusus: Persegi Panjang, Welch, Segitiga, Bartlett, Hanning, Hamming, Blackman, Gaussian, dan Kaiser.

Penting untuk memilih ukuran yang tepat dari bagian yang tumpang tindih untuk Window. Misalnya, ukuran tumpang tindih bukan nol biasanya membantu mendeteksi perubahan antara bingkai data yang berdekatan. Namun, ini membutuhkan waktu komputasi yang lebih lama. Ukuran yang tumpang tindih juga terkait dengan ukuran matriks hasil STFT.

Jika ukuran bagian FFT lebih besar dari ukuran Window, angka nol akan diletakkan di kedua sisi setiap segmen data ber Window. Ini biasanya meningkatkan resolusi frekuensi. waktu.

Jika grafik gambar diplot dari hasil, Anda mungkin melihat lebih jelas bagaimana frekuensi berubah seiring 
Harap dicatat bahwa kegunaan STFT terbatas karena merupakan metode resolusi tetap. Analisis multi-resolusi, seperti transformasi wavelet, harus dilakukan untuk meningkatkan analisis sinyal untuk beberapa aplikasi.(OriginPro, https://www.originlab.com)

\section{HASIL DAN PEMBAHASAN}

Data hasil pembacaan dari picoscope seperti dibawah ini :

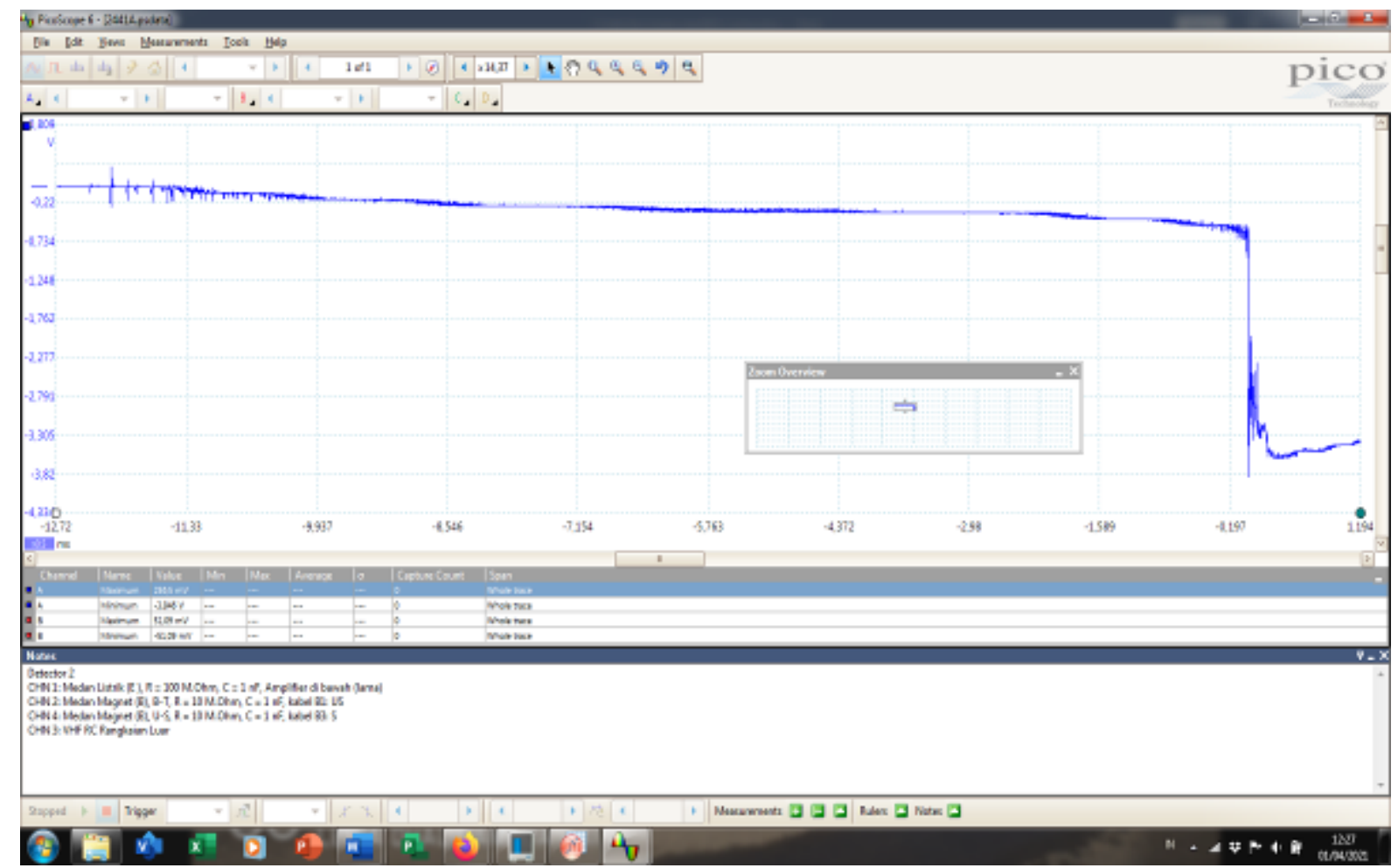

Gambar 4. Hasil Pembacaan picoscope

Gelombang yang terbaca akan dikonversikan berupa format txt dan csv untuk di olah menjadi analisis gelombang, dimana data yang berdomain waktu di konversikan menjadi domain frekuensi.

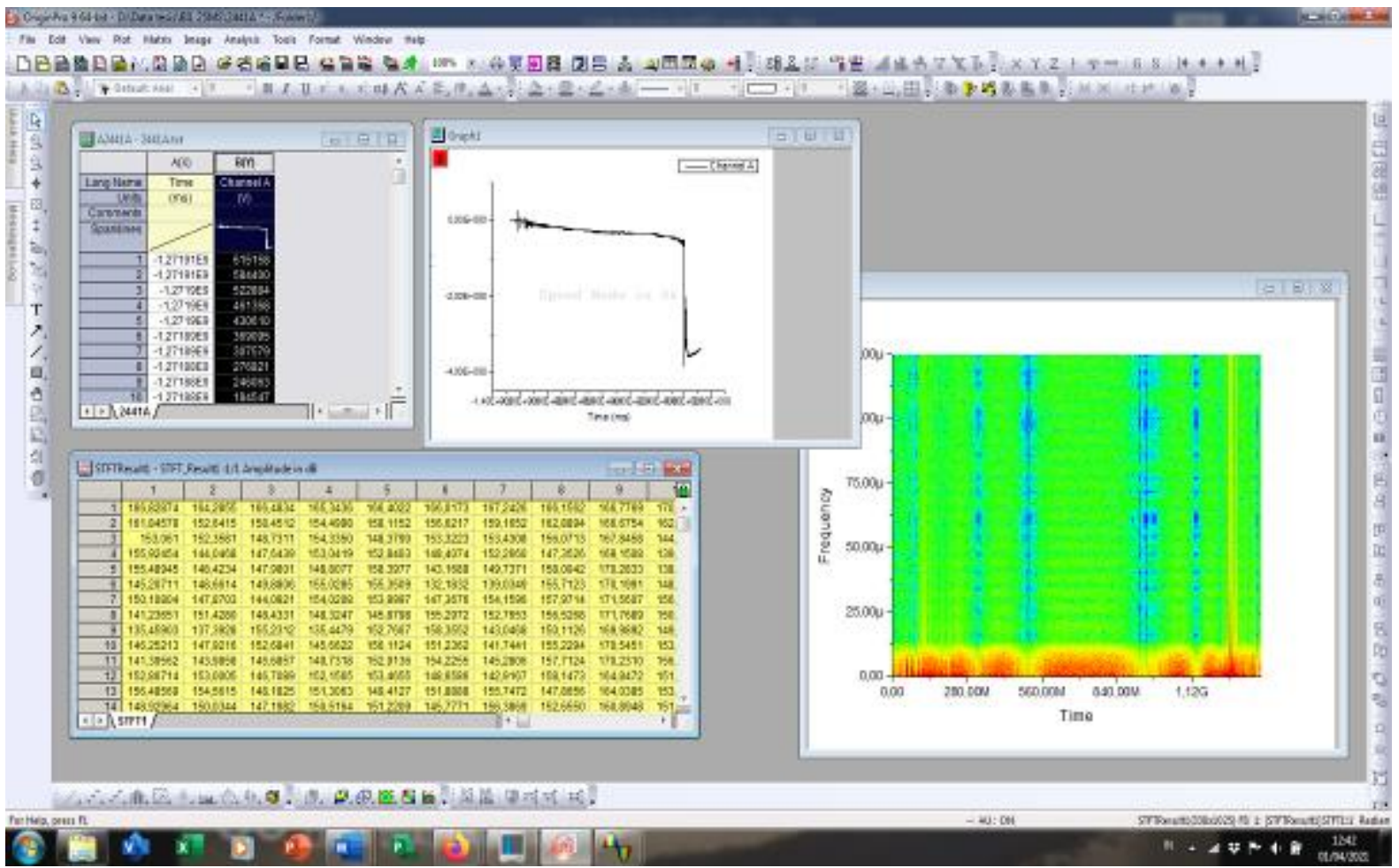

Gambar 5. Proses konversi data 
Hasil analisis gelombang yang diperoleh dengan menggunakan FFT didapat sebagai berikut :

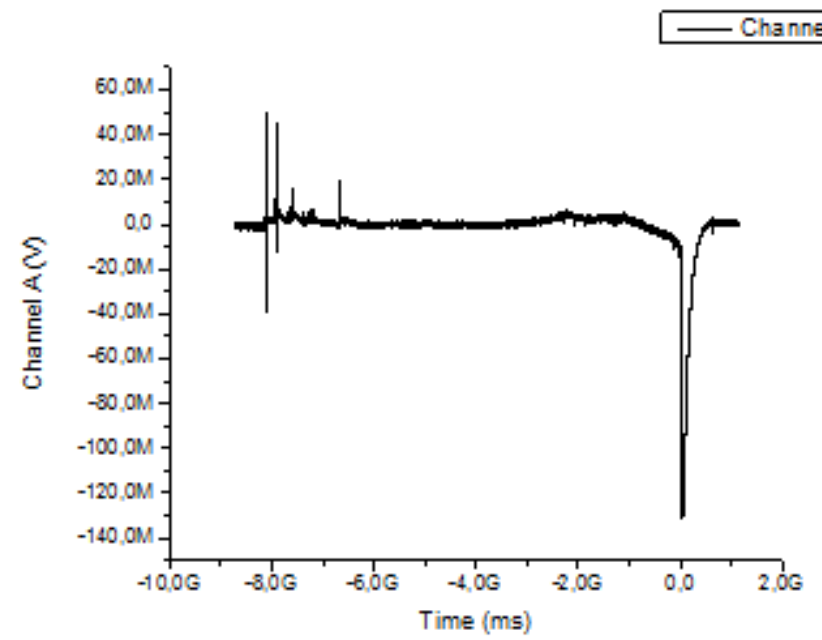

Gambar 6. Hasil analisis STFT dari citra osiloskop

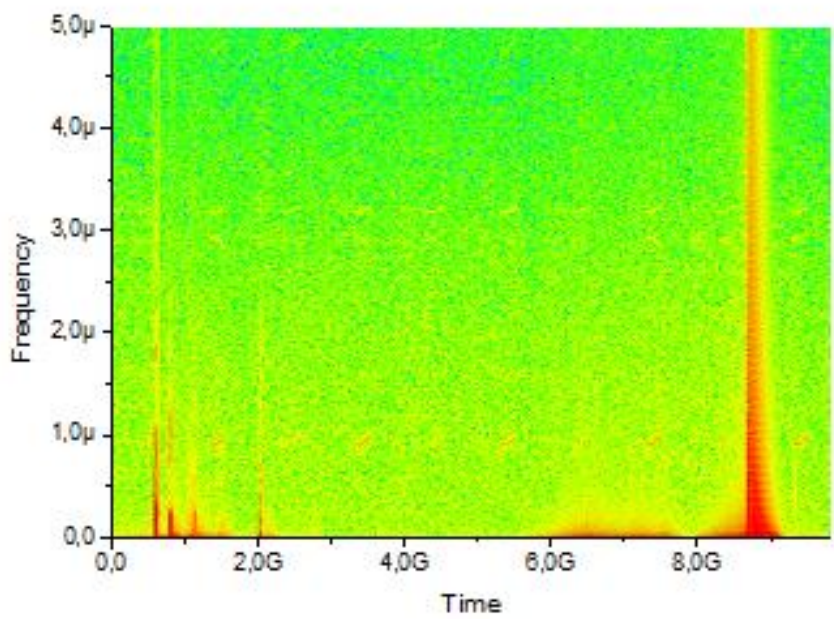

Gambar 7. Spektogram Hasil analisis 2D spektrum dengan aplikasi OriginPro

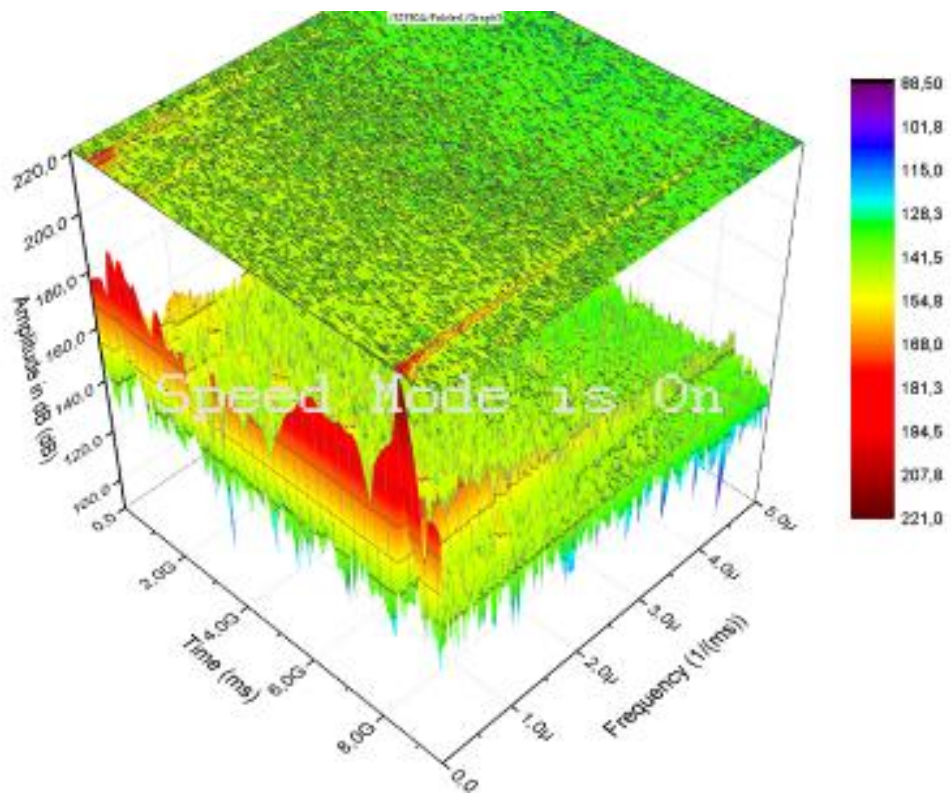

Gambar 8. Spektogram Hasil analisis 3D spektrum dengan aplikasi OriginPro 


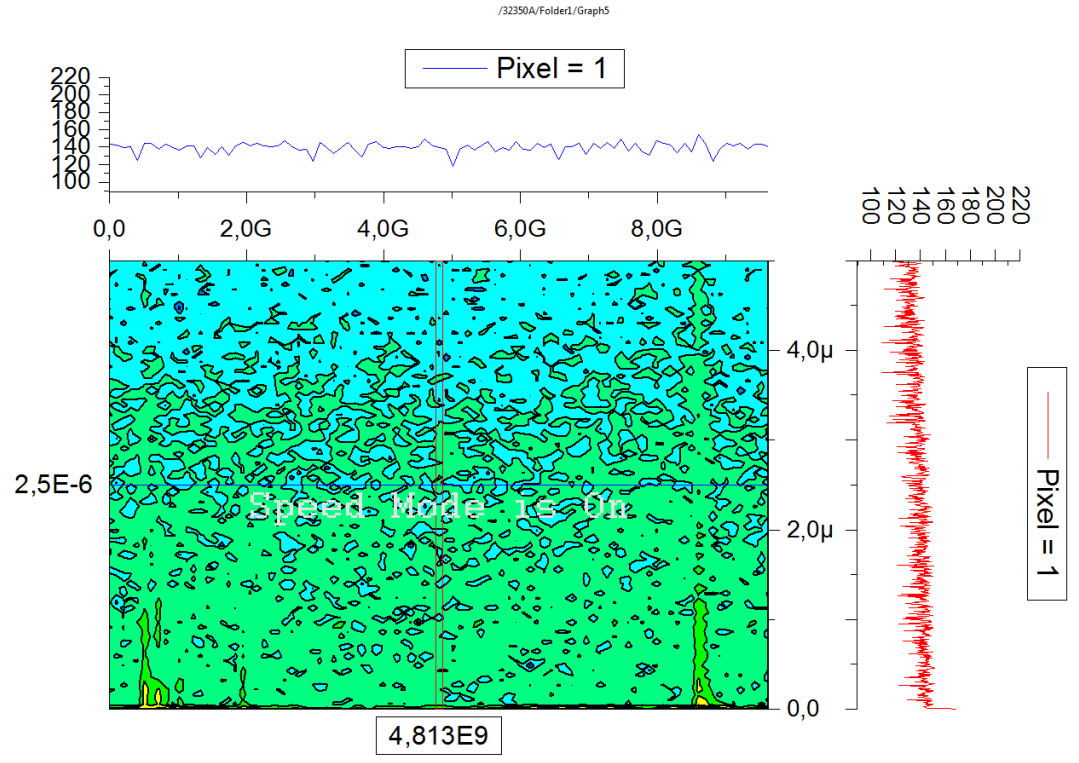

Gambar 9. Grafik kontur spektrum gelombang

Dari perhitungan dengan analisa fourier didapat tampilan spektrum gelombangnya, analisis spektrum gelombang ini digunakan untuk menentukan pola sinyal yang terbaca oleh picoscope.

\section{SIMPULAN}

Transformasi Fourier digunakan untuk mengubah domain spasial pada citra menjadi domain frekuensi. Penggunaan aplikasi OriginPro untuk menganalisis citra gelombang yang didapat dari pembacaan osiloskop, sangat membantu sekali, terlebih untuk menganalisis bentuk gelombang berdasarkan perubahan frekuensi terhadap waktu. Transformasi Fourier dari sinyal memberi tahu frekuensi apa yang ada dalam sinyal dan dalam proporsi apa.

\section{DAFTAR PUSTAKA}

S. Zulka Hendri* dan Ariadi Hazmi** and P. T. Elektro, "KARAKTERISTIK PRELIMINARY BREAKDOWN PETIR DOWNWARD LEADER SEBELUM SAMBARAN NEGATIF PERTAMA,” J. Nas. Tek. Elektro, vol. Vol:3 No. , no. 1, pp. 25-31, 2014.

G. Maslowski, "Spectral Characteristics of the Electric Field Related to the Preliminary Breakdown Stage of Cloud-toGround Lightning Flashes," no. June, pp. 15-20, 2014.

M. Ismail, M. Rahman, V. Cooray, S. Sharma, P. Hettiarachchi, and D. Johari, "Electric Field Signatures in Wideband, $3 \mathrm{MHz}$ and $30 \mathrm{MHz}$ of Negative Ground Flashes Pertinent to Swedish Thunderstorms," Atmosphere (Basel)., vol. 6, no. 12, pp. 1904-1925, 2015.

elsevier Francesco Lattarulo, Electromagnetic Compatibility in Power Systems. 2007.

E. A. Kasatkina, O. I. Shumilov, Y. A. Vinogradov, and A. N. Vasilyev, "Spectral characteristics of atmospheric pressure and electric field variations under severe weather conditions at high latitudes," pp. 6613-6626, 2006.

P. Hall and U. S. River, SPECTRAL ANALYSIS OF SIGNALS Petre Stoica and Randolph Moses. 2004.

N. A. Ahmad, Z. A. Baharudin, M. Fernando, and V. Cooray, "Radiation field spectra of long-duration cloud flashes," vol. 95, no. September 2014, pp. 91-95, 2015.

Q. Li, K. Li, and X. Chen, "Journal of Atmospheric and Solar-Terrestrial Physics Research on lightning electromagnetic fields associated with first and subsequent return strokes based on Laplace wavelet," vol. 93, no. 3, pp. 1-10, 2013.

M. Riza, M. Esa, M. Riduan, and V. Cooray, "Wavelet analysis of the fi rst electric fi eld pulse of lightning fl ashes in Sweden," Atmos. Res., vol. 138, pp. 253-267, 2014.

James W. Cooley and John W. Tukey, An algorithm for the machine calculation of complex Fourier series. Math. Comput. 19, 297 - 301 (1965).

James C. Schatzman, Accuracy of the discrete Fourier transform and the fast Fourier transform. SIAM J. Sci. Comput. 17 (5), 1150 - 1166 (1996).

Matteo Frigo and Steven G. Johnson. FFTW. http://www.fftw.org/.

M. Frigo and S. G. Johnson. The Design and Implementation of FFTW3. Proceedings of the IEEE 93 (2), 216 - 231 (2005).

Thomas H. Cormen, Charles E. Leiserson, Ronald L. Rivest, and Clifford Stein. Introduction to Algorithms, Second Edition. MIT Press and McGraw-Hill, 2001. Chapter 30: Polynomials and the FFT, pp.822-848. 
William H. Press, Brian P. Flannery, Saul A. Teukolsky, William T. Vetterling. 1992. Numerical Recipes in C: The Art of Scientific Computing. Cambridge University Press

M.Greitans. 2005. Adaptive STFT-like Time-Frequency analysis from arbitrary distributed signal samples. International Workshop on Sampling Theory and Application, Samsun, Turkey.

Julius O. Smith III and Xavier Serra. PARSHL: An Analysis/Synthesis Program for Non-Harmonic Sounds Based on a Sinusoidal Representation. Proceedings of the International Computer Music Conference (ICMC-87, Tokyo), Computer Music Association, 1987.

Bendat, J.S. and Piersol, A.G. 1986. Random Data: Analysis and Measurement Procedures, second edition. Wiley Interscience, New York.

Smith, Julius O. 2003. Mathematics of the Discrete Fourier Transform (DFT). W3K Publishing. 